\title{
From Epistemology to Structural Equation Modeling: An Essential Guide in Understanding the Principles of Research Philosophy in Selecting the Appropriate Methodology
}

\author{
Ahmad Saifalddin Abu-Alhaija \\ Arab Open University, Department of Management and Marketing, Faculty of Business Studies, Dammam, Saudi Arabia
}

Correspondence Author: Ahmad Saifalddin Abu-Alhaija, Arab Open University, Department of Management and Marketing, Faculty of Business Studies, Dammam, Saudi Arabia.

E-mail:- ahmadsaifalddinyousef.phd14@grad.putrabs.edu.my

Received date: 15 July 2019, Accepted date: 28 September 2019, Online date: 30 September 2019

Copyright: (C) 2019 Ahmad Saifalddin Abu-Alhaija, This is an open-access article distributed under the terms of the Creative Commons Attribution License, which permits unrestricted use, distribution, and reproduction in any medium, provided the original author and source are credited.

\begin{abstract}
This paper aims to explain the research philosophy in terms of the ontological and epistemological assumptions. It explicates the principles of research designs used in developing proper research formats. The paper primarily contrasts post-positivism with constructivism paradigms in terms of philosophical beliefs, methodology, and methods. It also focuses on the key research perspectives that can assist scholars in investigating different concepts and issues. A review of the literature has been employed to provide further understandings on research philosophy and methodology. Scholars have given inadequate attention to philosophical foundations in examining the proposed research models. The study specifically argues that some researchers lack the proper understanding on the core philosophical and methodological assumptions in the social science. Researchers from all fields are also asked to identify implicitly or explicitly the philosophical assumptions of their studies in achieving research objectives. It is vital to understand that there are two important ontological perspectives, namely objective ontology and subjective ontology. This will determine the researcher's epistemology that is being used in research. More specifically, researchers use specific research epistemology based on their ontology. Post-positivism paradigm (quantitative approach) is informed by objective ontology while constructivism (qualitative approach) is informed by subjective ontology. This paper argues that the selection of accurate research philosophy and design is primarily dependent on the research questions and objectives. Moreover, it concludes that researchers can use either CB-SEM or VB-SEM based on the research orientation (confirming vs predicting). Additional suggestions and directions are clearly provided. It is hoped that the propositions provided in the study would inspire future researchers in emerging efficient research models.
\end{abstract}

Keywords: Ontology, epistemology, research philosophy, quantitative, qualitative, methodology, methods, Structural Equation Modeling (SEM)

\section{INTRODUCTION}

Research is primarily conducted to solve a problem, seek an answer (May and Williams, 2002) or discover new knowledge (Hughes and Sharrock, 2016; Ryan et al., 2009). Research also leads to additional justifications and better understandings on a specific issue (May and Williams, 2002; Ryan et al., 2009). However, the credibility of research results and conclusions depends on the procedures that are used in the research investigation (May and Williams, 2002). In this regard, successful research investigations demand using appropriate research approaches. Understanding the research approach is considered to be a necessary procedure as this would lead to convincing results. The research approach includes three critical components, namely research philosophy, design, and methodology (Creswell, 2014). Researchers are supposed to properly identify their research approaches. All research projects rely on specific philosophical foundations (Hunt, 2015), and it is assumed that each approach includes distinct philosophical assumptions and procedures (Creswell, 2014). It is vital to recognize the nature and implications of different research approaches. In this regard, there are significant differences between quantitative and qualitative research approaches in terms of philosophical assumptions, research strategies, and methods (Creswell, 2014).

There are always ontological, epistemological, and methodological assumptions in all research projects (Hunt, 2015). "Research philosophy classifications such as ontology, epistemology, and anxiology and their conflicting applications to the 'quantitative-qualitative' debates, are a major source of dilemma to research students in establishing their relevance to subjects 
Citation: Ahmad Saifalddin Abu-Alhaija, From Epistemology to Structural Equation Modeling: An Essential Guide in Understanding the Principles of Research Philosophy in Selecting the Appropriate Methodology. Australian Journal of Basic and Applied Sciences, 13(9): 122-128. DOI: 10.22587/ajbas.2019.13.9.12

areas and discipline" (Mkansi and Acheampong, 2012, p.1). Most research papers also assumed that all researchers understand the research approaches and underpinning philosophies. However, the actual case shows that sometimes, researchers and readers lack this understanding. Therefore, this might lead to confounding interpretations of research approaches and results. This highlights the need to better understand the ontological and epistemological foundations that guide different research designs. It is also advised that the philosophical foundations of research should be explicitly or implicitly identified based on rigorous and sound reasonings (Hunt, 2015). Further to this, the purpose of this paper is to review the research philosophy and discuss its foundations and assumptions. This paper primarily aims to provide an understanding of the underpinning philosophy behind post-positivist research and constructivist research. Thus, important and necessary comparisons will be made between different research paradigms in terms of research philosophy, methodology, and methods. The present paper may assist researchers to be aware of the ontological and epistemological assumptions of different studies. It is hoped that those who are new to the research field in social science would be able to use this review paper as a valuable platform to learn about using proper research designs and statistical tools.

\section{LITERATURE REVIEW}

\section{Research Philosophy}

Research philosophy guides researchers in the selection of the most convenient approach and technique in research (Ates, 2008). Research philosophy can be discussed in terms of ontology and epistemology. Epistemology explains how researchers acquire the truth or knowledge (Crotty, 1998). "An epistemology is a theory of knowledge of what can be known and what criteria it uses to justify it being knowledge" (Petty et al., 2012). The way we look at our world is called a worldview, paradigm, or epistemology (Creswell, 2014; Mertens, 2009). However, there is a clear difference between ontology and epistemology. Ontology reflects the philosophy or nature of reality (Mertens, 2009; Petty et al., 2012; Raddon, 2010; Sobh and Perry, 2006), while epistemology reflects the nature of knowledge (Mertens, 2009; Raddon, 2010) or the ways used to acquire knowledge of this reality (Petty et al., 2012). Epistemological assumptions refer to the appropriate criteria that are used in evaluating knowledge claims (Hunt, 2015). Epistemology also represents the relationship between reality and researchers. It reflects on how researchers can recognize or understand the reality (Feast, 2010)._It is important to understand that there are two important ontological perspectives, namely, objective ontology and subjective ontology. These determine which epistemology or research paradigm that should be used in research. Epistemology is informed by ontology. Research paradigms are considered critical drivers of good research (Bård et al., 2011). In this regard, categorizing all psychological and educational research into a specific number of research paradigms is a complex effort (Mertens, 2009). According to Creswell (2014) and Mertens (2009), there are four research paradigms (Worldviews), namely 1) post-positivism or positivism, 2) constructivism, 3) transformativism, and 4) pragmatism. Nonetheless, according to Petty et al. (2012), there are two important research paradigms, namely 1) post-positivism (positivism) and 2) constructionism (interpretivism).

A research paradigm includes specific philosophical assumptions that guide the researchers' reasonings and actions (Mertens, 2009). Positivism or post-positivism paradigm was "developed during the enlightenment in the eighteenth century when rational thought and reason replaced religion and faith to explain phenomena" (Petty et al., 2012). Objectivity and generalizability are important assumptions for both positivists and post-positivists. However, post-positivists suggest that researchers need to fine-tune their understanding of the meaning (or truth) based on a probable view instead of a certain view (Mertens, 2009). Researchers in post-positivism examine the research problems to identify and measure the factors that could probably affect specific outcomes (Creswell, 2014). According to the post-positivism paradigm, researchers could recognize the "reality" within a specific level of probability (Mertens, 2009). Post-positivist worldview is sometimes known as positivist or post-positivism (Creswell, 2014), empirical science (Creswell, 2014; Petty et al., 2012), or scientific method (Petty et al., 2012). Knowledge for positivist scholars is considered observable and measurable (Assalahi, 2015). Researchers observe and measure the objective reality that exists out there. Examining individuals' behaviors through numeric measurements is dominant in the post-positivists' paradigm (Creswell, 2014).

Objectivism describes the ontological-stance for the positivism perspective (Assalahi, 2015). In other words, positivism is informed by objective ontology. According to Raddon (2010), researchers in positivism search for objective knowledge. Ontological assumption of positivism or post-positivism paradigm assumes there is a single objective reality (Petty et al., 2012). Positivists strictly follow specific research procedures in order to prevent or minimize their bias (Assalahi, 2015; Mertens, 2009). In post-positivism paradigm (objective otology), researchers separate their experiences and knowledge from the study (Petty et al., 2012). Researchers in positivism use objective measurements. Positivism/post-positivism paradigm assumes that researchers can observe and measure a stable reality in a systematic, logical, and rigorous way to have objective facts or knowledge (Petty et al., 2012). On the other hand, constructionism is informed by subjective ontology. Researchers in constructionism aims to understand individuals' explanations and perceptions (Ates, 2008). Scholars admit that their experiences have an impact on their understandings and interpretation. This bias or subjectivity is called reflexivity (Petty et al., 2012). This means it is hard to separate researchers' understanding from absolute reality. Based on the ontological foundation of interpretivism, reality is considered to be socially constructed. (Petty et al., 2012). This implies that individuals may form different understandings and interpretations of specific experience or situation (Petty et al., 2012). One reality may lead to various perceptions. In other words, researchers may find several realities of one experience based on people's different perceptions. In interpretivism, researchers may quote some participants' experiences, stories, opinions, and words in order to show and reflect different voices and views (Petty et 
Citation: Ahmad Saifalddin Abu-Alhaija, From Epistemology to Structural Equation Modeling: An Essential Guide in Understanding the Principles of Research Philosophy in Selecting the Appropriate Methodology. Australian Journal of Basic and Applied Sciences, 13(9): 122-128. DOI: 10.22587/ajbas.2019.13.9.12

al., 2012). In post-positivism, the research question is specifically stated. On the other hand, interpretive researchers broadly state the research question in order to capture different understandings and views. This approach can help the study to evolve based on the findings and data obtained (Petty et al., 2012).

Determining the epistemology guides researchers to adopt a specific research methodology. In this regard, methodology determines the techniques used by researchers to discover a specific reality (Sobh and Perry, 2006). Positivists use commonly deductive methodology (Ates, 2008; Raddon, 2010). Surveys are considered common techniques for positivists' research (Ates, 2008; Easterby-Smith et al., 2015). Positivist researchers use a) the research survey, as a proper methodology, and b) statisticalanalysis, as a specific research method (Crotty, 1998). Research survey, as a specific methodology, is generally related to positivist epistemology (Easterby-Smith et al., 2015). This means that the application of a convenient methodology actually depends on researchers' selected ontology and epistemology (e.g., post-positivism is informed and influenced by objectivism).

The knowledge framework includes four main elements: 1) epistemology, 2) theoretical-perspective, 3) methodology, and 4) research methods (Crotty, 1998), which, according to Feast (2010), are hierarchically organized. The post-positivist assumption is considered a classical research form (Creswell, 2014). According to objectivism, there is objective meaning, knowledge, or truth waiting to be discovered in our world; i.e. objectivism underpins the positivist perspective. Objectivist researches use quantitativemethods, while constructionist or subjectivist researches use qualitative-methods (Crotty, 1998). According to Mertens (2009), both qualitative and quantitative researches are considered a methodology and not a specific research paradigm. Quantitative research is a common methodology for post-positivism paradigm (Creswell, 2014; Mertens, 2009). Assalahi (2015) stated that quantitative methodology defines the research methods for data collection and analyses. On the other hand, the meaning or knowledge for constructionism is considered subjective. Researchers engage with various realities in this world to construct a specific truth or meaning (Crotty, 1998). This indicates that individuals could establish or construct various meanings and realities even for the same object or issue (Crotty, 1998; Feast, 2010). Further to this, there are factual answers based on positivist epistemology. Researchers propose a number of hypotheses and then gather data to test the hypotheses (Easterby-Smith et al., 2015). Post-positivist researchers begin with a specific theory, then collect the data that may support or refute that theory, and finally make the required modifications or reviews (Creswell, 2014). In other words, positivists commence the research process by proposing specific hypotheses based on established theories and then deciding whether the research results confirm these theories or the other way around (Assalahi, 2015).

\section{Research Design}

Research design reflects the research activities and procedures employed to achieve specific objectives (Easterby-Smith et al., 2015). It is also considered the road map for a specific research investigation in its attempt to answer the research questions (Cooper and Schindler, 2008). This is called the procedures of inquiry (Creswell, 2014). Research design includes several research decisions, such as research purpose, investigation types, researchers' interference, research setting, research measurements, unit of analysis, sampling design, time horizon, data collection, and data analysis (Sekaran, 2007). In this regard, research design reflects the main scheme or plan for the research measurements, data collection, data analysis (Cooper and Schindler, 2008; Creswell, 2014) and data interpretation (Creswell, 2014). This plan or design reflects the research program (over-all scheme) which determines the activities that researcher needs to perform starting from the hypotheses development to data analysis (Cooper and Schindler, 2008). Identifying appropriate methodological assumptions (research designs) are considered vital for any research in order to generate new knowledge (Hunt, 2015).

Moreover, there are four stages based on the sequence of research process as suggested by Cooper and Schindler (2008). The first stage refers to the research design strategy, which determines data collection design, sampling design, instrument development, and pilot testing. The second stage refers to data collection, the third stage is related to data analysis and interpretation, and the fourth stage refers to research reporting. Researchers are thus advised to consider appropriate research designs to produce significant understandings (Hunt, 2015), as the first stage of research (i.e. research design) would affect the whole research process.

Basic or fundamental research aims to a) enhance the understanding of specific issues or problems that regularly happen, and b) to search for appropriate ways to handle or solve these problems. Basic research concentrates on testing existing theories (Hale, 2011). Knowledge generated from basic research could be used in the future to solve specific problems. Researchers mainly engage in this kind of research to equip themselves with the desired knowledge on specific problems with the intentions to suggest appropriate solutions (Sekaran, 2007). It is anticipated that practitioners would use the practical implications or the knowledge generated from the basic research to enhance their understandings on specific outcomes and issues. In this regard, the purpose of the study might be exploratory, descriptive, or testing specific hypotheses (Sekaran, 2007) based on the nature of the study and research questions. Research projects can be generally categorized into three approaches, namely a) quantitative, b) qualitative, and c) mixed methods (Creswell, 2014; Petty et al., 2012). As a specific decision in research design, researchers may use one of these approaches to answer the research questions (Creswell, 2014). In other words, scholars determine the proper research approach mainly based on the research question (Petty et al., 2012). It has been concluded that interpretivism and post-positivism mainly underpin qualitative and quantitative studies respectively (Petty et al., 2012). In this regard, researchers equate "positivist or postpositivist" with "quantitative." (Hunt, 2015). Quantitative research is used to measure customer knowledge, opinions, attitudes, or behaviors (Cooper and Schindler, 2008). Quantitative scholars also attempt to test the existing theories as a way to answer specific research questions (Creswell, 2014). In quantitative studies, researchers use established theories to explain or 
Citation: Ahmad Saifalddin Abu-Alhaija, From Epistemology to Structural Equation Modeling: An Essential Guide in Understanding the Principles of Research Philosophy in Selecting the Appropriate Methodology. Australian Journal of Basic and Applied Sciences, 13(9): 122-128. DOI: 10.22587/ajbas.2019.13.9.12

predict the relationships between particular research variables (Creswell, 2014). "Quantitative research helps to explain phenomena by collecting numerical data. It tests hypotheses, controls variables, measures, identifies cause and effect, and through statistical analysis, aims to generalize findings to predict future events" (Petty et al., 2012).

Quantitative researchers mainly depend on the numbers and application of closed-ended questions. On the other hand, qualitative researchers depend on words and use open-ended questions studies in order to explore and understand a social case or individual problem (Creswell, 2014). Qualitative studies help researchers to understand human experiences within a specific context using texts (Petty et al., 2012). Quantitative researchers may use certain strategies, such as, experiments, while qualitative researchers may use other strategies, such as, case studies (Creswell, 2014). Qualitative research interprets various experiences and meanings to generate further understanding (Petty et al., 2012), and it focuses on details. In qualitative studies, researchers have an important role in the construction of knowledge (Petty et al., 2012) as their perceptions have an impact on their understandings. Furthermore, the mix methods approach involves both quantitative and qualitative data (Creswell, 2014). It encompasses both quantitative and qualitative approaches. Researchers use mixed methods research based on the research nature and objective. Creswell (2014) stated that choosing mixed methods research would assist in acquiring a better understanding of a research problem compared to choosing a dedicated quantitative or qualitative research approach. The selection of a research approach is influenced by the research problem, the researcher's personal experience, and the study's audiences (Creswell, 2014).

In interpretivism, researchers use inductive reasoning strategies. They use their own data in order to build specific patterns, themes and categories (Petty et al., 2012). Qualitative researchers use inductive thinking approach (Creswell, 2014). This reasoning or research approach leads to a comprehensive explanation of a particular phenomenon or theory (Petty et al., 2012). Research process moves from particular to general themes (Creswell, 2014). Using inductive reasoning strategies, qualitative researchers depend on data in forming their theoretical assumptions and general research themes. On other hand, quantitative researchers use a deductive approach as their reasoning approach. Researchers use a deductive approach in order to test research hypotheses or theoretical assumptions through observational and empirical methods (Petty et al., 2012). For instance, quantitative researchers would primarily depend on specific theories, such as the theory of planned behavior or theory of self-regulation, as convenient theoretical backgrounds, to explain how the research variables are expected to be related. Quantitative researchers use specific theories deductively (Creswell, 2014). More specifically, the deductive approach shows that researchers 1) test or validate a specific theory, 2) test the hypotheses from the theory, 3) operationalize the variables derived from the theory, and finally, 4) select the proper instruments to measure the variables (Creswell, 2014). In short, quantitative researchers use the deductive model of thinking while qualitative researchers use inductive model of thinking.

\section{Factor Analysis}

Factor analysis (FA) comprises of exploratory factor analysis (EFA) and confirmatory factor analysis (CFA) (Byrne, 2010; Thompson, 2004). EFA differs from CFA (Brown and Moore, 2012; Hair et al., 2010). According to Henson and Roberts (2006), EFA is an exploratory technique, and researchers use it to generate a theory. EFA is considered a precursor to CFA procedures (Gerbing and Hamilton, 1996). Researchers conduct EFA in the early stages of a research (Brown and Moore, 2012; Churchill, 1979) to develop a research scale and validate a construct (Brown \& Moore, 2012)., while CFA takes place in later stages (Brown and Moore, 2012; Churchill, 1979) based on theoretical and empirical foundations (Brown and Moore, 2012). The research objectives should be clearly determined as researchers conduct EFA to identify the latent constructs underlying a set of indicators (Fabrigar et al., 1999; Norris and Lecavalier, 2010). EFA is a valuable scale-development technique aimed at determining a convenient number of indicators (Gerbing and Anderson, 1988). However, principal component analysis (PCA) is more appropriate than EFA for data reduction purposes (Fabrigar et al., 1999; Norris and Lecavalier, 2010). Several scholars incorrectly consider PCA as a specific type of EFA. PCA and EFA reflect different statistical approaches that are used to reach different research goals (Fabrigar et al., 1999). EFA differs from PCA in terms of theoretical and practical perspectives (Norris and Lecavalier, 2010). It is important to recognize that PCA cannot be considered as a substitute for EFA, and PCA is not a factor analysis (Fabrigar et al., 1999).

EFA technique assumes that any indicator might be related to any factor (Henson and Roberts, 2006). Researchers use EFA in situations where research connections are unidentified (or unclear) between the observed and latent variables (Byrne, 2010). However, researchers use CFA as a multivariate technique to confirm or test pre-specified relationships (Hair et al., 2010). In CFA, researchers clearly rely on empirical studies, or specific theories, or on both sources in postulating particular relationships between the observed and latent variables (factors) (Byrne, 2010). "CFA is generally used to test theory when the analyst has sufficiently strong rationale regarding what factors should be in the data and what variables should define each factor" (Henson and Roberts, 2006, p.395). According to Hair et al. (2010), researchers can confirm or reject a specific grounded theory through CFA. CFA is considered an appropriate choice when researchers have sufficient hypothetical and empirical foundations. It is also used to test research hypotheses. On the other hand, EFA is a practical choice in situations when there is a limited hypothetical and empirical foundation to identify one specific model or a number of particular competing-models, (Fabrigar et al., 1999). The absence of a sufficient detailed-theory on the conceptual relationships leads researchers to use EFA in their initial analysis (Gerbing and Anderson, 1988). EFA is a data-driven approach (Brown and Moore, 2012), and researchers derive research factors from statistical findings (Hair et al., 2010). In contrast, CFA is a theory driven approach; and the plan of the analysis is driven based on specific theoretical relationships between indicators and latent factors (Schreiber et al., 2006). More specifically, research factors at CFA are derived from a specific theory (Hair et al., 2010). The CFA technique needs solid conceptual or empirical foundations as important guidelines to specify and evaluate the factor model (Brown and Moore, 2012). “When prior 
Citation: Ahmad Saifalddin Abu-Alhaija, From Epistemology to Structural Equation Modeling: An Essential Guide in Understanding the Principles of Research Philosophy in Selecting the Appropriate Methodology. Australian Journal of Basic and Applied Sciences, 13(9): 122-128. DOI: 10.22587/ajbas.2019.13.9.12

theory exists regarding the structure of the data, CFA should be considered as an alternative to EFA" (Henson and Roberts, 2006, p.409). CFA models include various parameters, such as, factor variances, factor loadings, and unique variances (Brown and Moore, 2012). Researchers use CFA to evaluate construct validity (Kline, 1998). Therefore, CFA is considered a vital analytical method for construct validation (Brown and Moore, 2012).

\section{Structural Equation Modeling (SEM)}

SEM technique includes a combination of statistical procedures and models (Hair et al., 2010; Kline, 1998, 2011), such as path analysis and confirmatory factor analysis (Kline, 1998). It aims to explain the relationships between the research variables (Hair et al., 2010). Researchers can explain individuals' behaviors with the ability to predict their future performance and behaviors through SEM (Davcik, 2014). Researchers use SEM, as a multi-variant procedure (that includes multiple regression and factor-analysis) in examining interrelationships between the measured and latent variables, and also among various latent variables (Hair et al., 2010). Researchers use the terms of structural equation modelling (SEM), analysis of covariance structures (ACS), covariance structure modelling (CSM), or covariance structure analysis (CSA) interchangeably (Kline, 2011). SEM technique is sometimes known by the name of specialized statistical programs, such as AMOS and LISREL (Hair et al., 2010).

SEM is described as a theory-based technique, and researchers should specify all relationships before estimating SEM (Hair et al., 2010). Having a grounded theory is vital to all multivariate techniques, and it is especially crucial for SEM since it is regarded as a confirmatory analysis (Hair et al., 2010). In this regard, SEM is a strong technique for theory testing (Martínez-López et al., 2013). Present social science researchers recognized two streams of SEM. The first stream refers to CBSEM, also known as latent-variable-analysis (LVA) or covariance-structure-analysis (CSA), which uses AMOS or LISREL programs. While the second stream refers to VB-SEM, also known as a component-based SEM or PLS, which uses Smart-PLS or SPSS programs (Davcik, 2014). Researchers use either CB-SEM or VB-SEM based on the research orientation. More specifically, CB-SEM, is regarded as strictly theory-driven. Researchers in this stream tend to confirm the theoretical assumptions and parameters accuracy, while researchers in VB-SEM tend to focus primarily on the predictive power of the hypothesized-model (Davcik, 2014). This shows the different objectives of each stream. VBSEM is also based on theory, but it is primarily data-driven (Davcik, 2014). This shows the significance of data at VBSEM as it is mainly a predictive tool. Moreover, researchers through CB-SEM attempt to confirm specific theories (Davcik, 2014). For instance, researchers may examine the influences of independent variables on specific dependent variables by confirming theoretical assumptions based on selected theory or theories. SEM is considered the most dominant multi-variant technique for testing a specific behavioural-theory (Hair et al., 2010). According to Modeling and Lix (2010), SEM is an appropriate technique for theory-testing. It helps researchers to explain the relationships between multiple research variables (Hair et al., 2010). Scholars use SEM to prove a specific theoretical model in a quantitative form (Chui, 2011). SEM technique uses CFA to confirm that specified observed-variables based on the research model actually represent specific research constructs (latent variables) (Modeling and Lix, 2010). Confirmatory modelling strategy is a straightforward application for SEM, in which, researchers use SEM to assess how well a specific research model fits the data (Hair et al., 2010).

Researchers use SEM effectively in addressing various non-experimental research concerns or problems (Byrne, 2010). They also consider SEM as a flexible technique in examining how specific things are linked or related to each other (Hair et al., 2010). SEM is a flexible statistical procedure allowing researchers to examine the interrelationships among various independent and dependent variables (Chui, 2011). In this regard, SEM can be used as an appropriate technique for testing direct and indirect influences. The maximum likelihood method is used to estimate the structural equation models, as using this method is important in testing the proposed relationships between the research variables (Arbuckle, 2010). In sum, SEM is a convenient technique for the analysis of models. In SEM, researchers can use Amos, EQS, or LISREL programs. However, Amos is more user-friendly compared to the others (Kline, 1998). AMOS is an acronym that stands for analysis-of-moment-structures (Byrne, 2010). Many researchers from social sciences use AMOS mainly due to its practicality (Chui, 2011). For instance, Amos has a special estimation technique for treating missing data (Kline, 1998). Furthermore, researchers should understand the nature of reflective and formative constructs in order to specify the right measurement model. There are theoretical and empirical differences between formative and reflective constructs (Davcik, 2014). For instance, omission of any reflective indicators will not change the meaning of research construct (latent variable), while omission of any formative indicator will alter or affect the meaning of research construct (Davcik, 2014). This difference shows the significance of understanding the research variables in terms of "the construct-indicator relationship". It is important to be aware that the nature of this relationship dictates the research measurement as well. In addition to this, it is noted that psychometric constructs, such as personality and attitudes are reflective while organizational constructs, such as, marketing mix are formative (Davcik, 2014). Based on this, service quality perception, customers' satisfaction, and loyalty reflect attitudes and are referred to as reflective constructs (e.g., Abu-alhaija et al., 2018a; Abu-Alhaija et al., 2019; Abu-Alhaija et al., 2018b). In terms of the relationship between construct and indicator, it is observed that the direction of causality is from the construct to indicator for reflective constructs, while it is from the indicator to the construct for formative constructs (Davcik, 2014).

Researchers should evaluate the model fit (Modeling and Lix, 2010). Identifying how well a research model explains the data is referred to as the model-fit evaluation (Kline, 2011). Adequate goodness-of-fit means that the proposed relationships are accepted, whereas inadequate goodness-of-fit reflects invalid relationships (Byrne, 2010). In general, there are three measures that researchers use for the model fit evaluation in CB-SEM (Modeling and Lix, 2010; Davcik, 2014), namely, a) absolute-fit, b) 
Citation: Ahmad Saifalddin Abu-Alhaija, From Epistemology to Structural Equation Modeling: An Essential Guide in Understanding the Principles of Research Philosophy in Selecting the Appropriate Methodology. Australian Journal of Basic and Applied Sciences, 13(9): 122-128. DOI: 10.22587/ajbas.2019.13.9.12

incremental-fit, and c) parsimonious-fit measures (Martínez-López et al., 2013; Modeling and Lix, 2010; Davcik, 2014). Researchers can decide to use one technique or more to evaluate the model fit (Modeling and Lix, 2010). Although there are various techniques for model-fit-evaluation, researchers repeatedly use the four main techniques, namely a) RMSEA (Root-MeanSquare-Error-of-Approximation), b) GFI (Goodness-of-Fit-Index), c) CFI (Comparative-Fit-Index), and d) SRMR (StandardizedRoot-Mean-Square-Residual) (Kline, 2011). In this regard, researchers are not conclusive on the best model fit measure or measures used in SEM (Modeling and Lix, 2010; Kline, 2011). However, they are usually motivated to use one or more techniques from each measure (Modeling and Lix, 2010). The techniques include Chi-square statistics, degrees-of-freedom (df), raito- $\chi^{2} / \mathrm{df}, \mathrm{GFI}, \mathrm{CFI}$, IFI, TLI, RMSEA, SRMR and RMR. Literature review shows that there are several tables presenting general guidelines on the accepted values for different measures of model-fit-evaluation. Researchers are encouraged to review these tables in order to decide wisely, as these tables occasionally present different guidelines with reasonable justifications.

\section{CONCLUSION}

Recent discussions of the scholars and research students on several research platforms, such as, Research Gate and Facebook groups highlight the need for a better understanding of research philosophies and assumptions. This paper discussed different philosophical stances in terms of ontology and epistemology. It is found that epistemology is primarily informed and influenced by ontology. For instance, positivism or post-positivism paradigm is informed by objective ontology while constructivism is informed by subjective ontology. It is argued that understanding different philosophical stances and research designs would assist researchers in building a proper research design and accordingly a solid knowledge. This paper shows that it is considered vital to understand the principles of research design and its suitable methods based on the research objective and nature. It is concluded that both quantitative and qualitative research have different philosophical assumptions and research designs. For instance, postpositivism underpins quantitative research, while constructivism underpins qualitative research. Moreover, using both quantitative and qualitative approaches would further enhance researchers' understanding of research problems. In the paper, we argued that proper research design draws from a proper research philosophy and the selection of accurate research philosophy is primarily dependent on the research questions and objectives. Further to this, it is assumed that an understanding of the philosophical assumptions of quantitative and qualitative research may lead to solid and effective research results, which in turn, leads to proper and useful implications. Despite researchers utilizing previous valid scales, they mainly adapt these scales in terms of dimensions, language, and research context. In addition, some researchers tend to combine various scales into one as it fits their research objective and nature. Researchers are thus encouraged to perform exploratory factor analysis (EFA) and confirmatory factor analysis (CFA). Researchers can use either CB-SEM or VB-SEM based on the research orientation (confirming vs. predicting). It is argued that understanding the research philosophy of a study would guide the effective selection of a research methodology and method. Finally, this paper concludes that the research philosophy influences the research perspective, methodology, and methods.

\section{REFERENCES}

Abu-alhaija, A. S., Yusof, R. N. R., Hashim, H., \& Jaharuddin, N. S. (2018). Determinants of Customer Loyalty: A Review and Future Directions. Australian Journal of Basic and Applied Sciences, 12(7), $106-111$. https://doi.org/10.22587/ajbas.2018.12.7.17

Abu-Alhaija, Ahmad Saif-alddin, Yusof, R. N. R., Hashim, H., \& Jaharuddin, N. S. (2019). The influence of religious orientation on viewers' loyalty towards satellite TV channels: The case of Muslim viewers. Journal of Islamic Marketing, ahead-ofp(ahead-of-print). https://doi.org/https://doi.org/10.1108/JIMA-01-2018-0008

Abu-Alhaija, Ahmad Saifalddin, Yusof, R. N. R., Hashim, H., \& Jaharuddin, N. (2018). Customer Loyalty: Antecedents , Approaches and Influences of Culture and Religion. Journal of Islamic Management Studies, 2(1), 62-78.

Arbuckle, J. L. (2010). IBM SPSS ${ }^{\circledR}$ Amos $^{\text {TM }} 19$ User's Guide. Chicago, USA: Amos Development Corporation.

Assalahi, H. (2015). The Philosophical Foundations of Educational Research: a Beginner's Guide. American Journal of Educational Research, 3(3), 312-317. https://doi.org/10.12691/education-3-3-10

Ates, A. (2008). Fundamental Concepts In Management Research And Ensuring Research Quality: Focusing on Case Study Method. In 8th Annual European Academy of Management (EURAM) (pp. 1-35). slovenia.

Bård, T., Stephen, B. W., Dwayne, G. D., \& Bo, E. (2011). Paradigms in service research. Journal of Service Management, 22(5), 560-585. https://doi.org/https://doi.org/10.1108/09564231111174951

Brown, T. A., \& Moore, M. T. (2012). Confirmatory Factor Analysis. In Confirmatory Factor Analysis (p. 39). Boston University.

Byrne, B. (2010). Structural equation modeling with AMOS: Basic Concepts, Applications, and Programming (Second edition). New York, NY: Routledge: Taylor \& Francis Group. Retrieved from http://www.psypress.com

Chui, T. B. (2011). Antecedents of status consumption among women and the roles of hedonism and cultural value orientation. University Putra Malaysia.

Churchill, G. A. (1979). A Paradigm for Developing Better Measures of Marketing Constructs. Journal of Marketing Research, 16(1), 64-73. https://doi.org/10.2307/3150876

Cooper, D. R., \& Schindler, P. S. (2008). Business Research Methods (Internatio). McGraw-Hill Irwin.

Creswell, J. W. (2014). Research Design: Qualitative, Quantitative and Mixed methods. Journal of Chemical Information and Modeling (fourth, Vol. 53). California: SAGE. 
Citation: Ahmad Saifalddin Abu-Alhaija, From Epistemology to Structural Equation Modeling: An Essential Guide in Understanding the Principles of Research Philosophy in Selecting the Appropriate Methodology. Australian Journal of Basic and Applied Sciences, 13(9): 122-128. DOI: 10.22587/ajbas.2019.13.9.12

Crotty, M. (1998). Introduction: The Research Process. In The Foundations of Social Research: Meaning and perspective in the research process (pp. 1-17). California: SAGE.

Easterby-Smith, M., Thorpe, R., \& Jackson, P. R. (2015). MANAGEMENT AND BUSINESS RESEARCH (5th ed.). London: Sage Publications.

Fabrigar, L. R., Wegener, D. T., MacCallum, R. C., \& Strahan, E. J. (1999). Evaluating the use of exploratory factor analysis in psychological research. Psychol Method, 4(3), 272-299.

Feast, L. (2010). Epistemological Positions Informing Theories of Design Research: Implications for the Design Discipline and Design Practice. "Design and Complexity”, the 2010 Design Research, (40), 1-8. https://doi.org/9782981198525

Fischer, P., Greitemeyer, T., \& Kastenmuller, A. (2007). What Do We Think About Muslims? The Validity of Westerners' Implicit Theories About the Associations Between Muslims' Religiosity, Religious Identity, Aggression Potential, and Attitudes Toward Terrorism. Group Processes \& Intergroup Relations, 10(3), $373-382$. https://doi.org/10.1177/1368430207078697

Gerbing, D. W., \& Anderson, J. C. (1988). Updated aradigm for scale development incorporating unidimensionality. Journal of Marketing Research Research, 25(2), 186-192. https://doi.org/10.2307/3172650

Gerbing, D. W., \& Hamilton, J. G. (1996). Viability of exploratory factor analysis as a precursor to confirmatory factor analysis. Structural Equation Modeling, 3(1), 62-72. https://doi.org/10.1080/10705519609540030

Hair, J. F., Black, W. C., BABIN, B. ., \& Anderson, R. E. (2010). Multivariate data analysis (seven edit). Pearson Prentice Hall.

Hale, J. (2011). Understanding Research Methodology 5: Applied and Basic Research.

Henson, R. K., \& Roberts, J. K. (2006). Use of Exploratory Factor Analysis in Published Research: Common Errors and Some Comment on Improved Practice. Educational and Psychological Measurement, 66(3), $393-416$. https://doi.org/10.1177/0013164405282485

Hughes, J. A., \& Sharrock, W. W. (2016). The Philosophy of Social Research (3rd Editio). London: Routledge.

Hunt, S. D. (2015). Marketing Theory: Foundations, Controversy,Strategy, Resource-Advantage Theory (Second edi). New York, NY: Taylor \& Francis.

Kline, R. B. (1998). Software review: Software programs for structural equation modeling: Amos, EQS, and LISREL. Journal of Psychoeducational Assessment, 16(4), 343-364. https://doi.org/10.1177/073428299801600407

Kline, R. B. (2011). Principles and Practice of Structural Equation Modeling. Journal of Chemical Information and Modeling (Third Edit, Vol. 53). New York: The Guilford Press. https://doi.org/10.1017/CBO9781107415324.004

Martínez-López, F. J., Gázquez-Abad, J. C., \& Sousa, C. M. P. (2013). Structural equation modelling in marketing and business research. European Journal of Marketing, 47(1/2), 115-152. https://doi.org/10.1108/03090561311285484

May, T., \& Williams, M. (2002). Introduction to the philosophy of social research (1st Editio). London: Routledge.

Mertens. (2009). Research and Evaluation in Education and Psychology.

Mkansi, M., \& Acheampong, E. A. (2012). Research Philosophy Debates and Classifications: Students' Dilemma. The Electronic Journal of Business Research Methods, 10(2), 132-140.

Modeling, M. C., \& Lix, L. (2010). Structural Equation, 3, 137-161.

Norris, M., \& Lecavalier, L. (2010). Evaluating the use of exploratory factor analysis in developmental disability psychological research. Journal of Autism and Developmental Disorders, 40(1), 8-20. https://doi.org/10.1007/s10803-009-0816-2

Petty, N. J., Thomson, O. P., \& Stew, G. (2012). Ready for a paradigm shift ? Part 1 : Introducing the philosophy of qualitative research. Manual Therapy, 17, 267-274. https://doi.org/10.1016/j.math.2012.03.006

Raddon, A. (2010). Early Stage Research Training: Epistemology \& Ontology in Social Science Research. Retrieved February 10, 2019, from https://www2.le.ac.uk/colleges/ssah/documents/research-training-presentations/EpistFeb10.pdf

Ryan, B., Scapens, R. W., \& Theobold, M. (2009). The Philosophy of Financial Research. In Research Mthod and Methodology in Finance and Accounting (Second Edi). London: Cengage Learning.

S. Davcik, N. (2014). The use and misuse of structural equation modeling in management research. Journal of Advances in Management Research, 11(1), 47-81. https://doi.org/10.1108/JAMR-07-2013-0043

Schreiber, J. B., Nora, A., Stage, F. K., Barlow, E. a., \& King, J. (2006). Confirmatory Factor Analysis and Structural Equations Modeling: An Introduction and Review. The Journal of Educational Research, 99(6), 323-337. https://doi.org/10.3200/JOER.99.6.323-338

Sekaran, U. (2007). Research Methods For Business: A Skill Buiding Approach (Fourth). New Delhi: WILEY.

Sobh, R., \& Perry, C. (2006). Research design and data analysis in realism research. European Journal of Marketing, 40(11/12), 1194-1209. https://doi.org/10.1108/03090560610702777

Thompson, B. (2004). Exploratory and confirmatory factor analysis: Understanding concepts and applications. Washington, DC, US: American Psychological Association. https://doi.org/http://dx.doi.org/10.1037/10694-000 